\title{
PENGARUH LATIHAN PASSING BERPASANGAN STATIS DAN LATIHAN PASSING BERGERAK DINAMIS TERHADAP KETEPATAN PASSING PADA PERMAINAN FUTSAL
}

\author{
Risna Delila Putri Oktavia'), Didik Hariyanto ${ }^{2)}$ \\ IKIP Budi Utomo Malang \\ email: ${ }^{1}$ Risnadelila@gmail.com \\ 2.
}

\begin{abstract}
ABSTRAK
Berdasarkan hasil observasi dan wawancara yang dilakukan tentang kesalahan passing pada futsal putri terjadi dalam keadaan pertandingan tegang karena kondisi skor imbang, mampu memenangkan pertandingan diakhir catatan waktu, terkejut saat pemain membawa bola didatangi oleh lawan atau tergesa-gesa ingin segera mencetak gol karena keegoisan pemain itu sendiri. Passing dalam futsal tidak hanya sekedar 12 kali sentuhan tetapi banyak variasi passing seperti short passing dan long passing. Maka dari itu kualitas passing harus diperbaiki sejak dini pada peserta ekstrakurikuler atau pada klub futsal putri mengingat dalam permainan futsal passing sangat sering dilakukan.Metode penelitian yang digunakan dalam penelitian ini adalah eksperimen. Desain penelitian yang digunakan adalah Control Group pre-test post-test Design, (Suharsimi Arikunto, 2013). Berdasarkan hasil penelitian ada perbedaan pengaruh antara latihan passing berpasangan dan passing bergerak terhadap ketepatan passing pada peserta ekstrakurikuler futsal putri SMP Negeri 21 Malang. Hal ini dapat dilihat berdasarkan kedua kelompok eksperimen yang setelah dihitung menggunakan rumus uji beda mean mendapatkan nilai $\mathrm{t}_{\text {tes }}$ sebesar $0,226<\mathrm{ts}_{5 \%}(2,782)$ dan $\mathrm{ts}_{1 \%}(3,081)$, sehingga hipotesis alternative (Ha) diterima dan hipotesis nihil (Ho) ditolak.
\end{abstract}

Kata Kunci : pengaruh, passing berpasangan statis, passing bergerak dinamis, ketepatan passing.

\section{ABSTRACT}

Based on the results of observations and interviews conducted on passing errors in women's futsal occurred in a tense match due to the score score condition, being able to win the game at the end of the time record, surprised when the player brought the ball to the opponent or rushed to immediately score because of the player's selfishness own. Passing in futsal is not just 12 times touch but there are many variations of passing such as short passing and long passing. Therefore the quality of passing must be corrected early on for extracurricular participants or at women's futsal clubs considering that futsal passing is very often done. The research method used in this study was an experiment. The research design used was the Control Group pre-test post-test Design, (Suharsimi Arikunto, 2013). Based on the results of the study there are differences in the effect of passing and pairing passing on the accuracy of passing on futsal extracurricular members. daughter of Malang Middle School 21. This can be seen based on the two experimental groups which after being calculated using the different mean test formula get ttes of $0.226<t 55 \%(2.782)$ and ts $1 \%$ (3.081), so that the alternative hypothesis ( $\mathrm{Ha}$ ) is accepted and the null hypothesis (Ho) is rejected.

Keywords : influence, static passing, dynamic moving passing, passing accuracy.

Risna Delila. Pengaruh Latihan Passing Berpasangan Statis Dan Latihan Passing Bergerak Dinamis Terhadap Ketepatan Passing Pada Permainan Futsal 


\section{PENDAHULUAN}

Di era globalisasi seperti sekarang ini olahraga futsal mulai berkembang dan dikenal di seluruh Indonesia. Dimana olahraga futsal ini dianggap sebagai miniatur cabang olahraga sepakbola, yaitu dengan ukuran normal lapangan sepakbola panjang 100-110 meter dan lebar 90-100 meter sedangkan ukuran lapangan futsal standar internasional panjang 38 meter dan lebar 18 meter begitupun juga dengan material lapangan yang berbeda pula. Lapangan futsal yang beberapa tahun lalu menggunakan lapangan sintetis atau rumput buatan yang terdapat banyak butiran karet di dalamnya setelah perkembangan zaman dan minat masyarakat, lapangan futsal kini berubah menjadi lapangan yang terbuat dari papan yang dapat dibongkar dan dipasang dinamakan Vynil.

Menurut (Murhananto, 2008) Futsal adalah kata yang digunakan secara internasional untuk istilah permainan sepakbola dalam ruangan. Kata futsal singkatan dari football (sepakbola) dan sala (ruangan) dari bahasa Spanyol atau futeboll (Portugal/Brazil) dan salon (Prancis). Olahraga ini sangat cepat dan menarik sehingga membuat seorang pemain agar selalu siap menerima dan mengumpan bola dengan cepat dalam tekanan pemain lawan. Dengan lapangan yang sempit, permainan ini menuntut teknik penguasaan bola tinggi, kerja sama antar pemain, dan kekompakan tim.

Pada saat ini futsal di Indonesia sangat berkembang pesat pasalnya setiap instansi, sekolahan, dan universitas sudah memiliki tim futsal tetapi tidak tim putra saja dan tim putri juga dibentuk, banyak turnamen-turnamen digulirkan dengan berbagai kategori umum tanpa batasan umur untuk putri, antar instansi, antar sekolah dan antar mahasiswa putri bahkan yang sedang ramai bergulir pada saat ini yaitu Woman Pro Futsal League. Apalagi keberadaan futsal bukan lagi sebagai sebuah olahraga tetapi sudah berubah menjadi gaya hidup (life style). Futsal digemari berbagai kalangan anak kecil, remaja, maupun orang dewasa. Futsal menjadi pilihan alternatif untuk mengisi waktu luang atau melepas ketegangan dan stres akibat pekerjaan.

Olahraga futsal ini diperlukan berbagai macam teknik namun yang paling penting dan sangat riskan adanya kesalahan yaitu passing, namun tidak semua pelatih menyadari bahwa passing ini sangat dibutuhkan karena dalam futsal putri tidak semua materi pemain mampu bermain paling tidak hanya 1-2 orang yang mampu bermain dengan baik dan mempunyai teknik 
passing yang memadai. Pada dasarnya teknik ini harus dimiliki setiap pemain namun pada siswi putri yang baru mempelajari futsal sangat sulit dilakukan karena sebelumnya siswi putri tidak pernah melakukan olahraga yang berhubungan dengan bola sepak kecuali pada siswi putri yang telah terlatih sebelumnya mengikuti klub sepakbola atau tim futsal. passing merupakan teknik yang sangat diperlukan dan komponen yang sangat penting karena passing merupakan teknik yang mudah di lakukan dimana saja tanpa harus ada alat khusus. Tanpa passing permainan tidak akan pernah berjalan, passing yang akurat, keras dan tepat sangatlah berpengaruh terhadap berjalannya suatu pertandingan jika passing tidak sesuai sasaran maka diambil alihlah penguasaan permainan kita oleh lawan. Untuk mendapatkan hasil kualitas passing yang baik maka latihan harus dilakukan secara berkelanjutan continue.

Menurut (Timo S. Scheunemann, 2012) kurikulum dan pedoman dasar sepakbola Indonesia. Passing merupakan memindahkan bola mendatar atau di udara dari satu pemain ke pemain yang lainnya rekan 1 tim, dengan jarak yang bervariasi. Passing adalah bagian yang sangat penting dalam permainan olahraga futsal, permainan futsal memerlukan strategi dan ketepatan mengumpan dengan baik. Umpan menghubungkan semua pemain di seluruh bagian lapangan dan memungkinkan tim menciptakan serangan. Dalam permainan futsal, terdapat beberapa pilihan umpan, antara lain mengumpan jarak pendek (short passing), dan mengumpan panjang (long passing) ke teman satu tim. Umpan bisa dilakukan menyusur permukaan lapangan atau dengan mencungkil bola melewati kepala lawan, pemain memerlukan keterampilan mengumpan yang memadai. Untuk menjadi pemain futsal yang hebat, kita harus memperbaiki kemampuan kita dalam mengumpan. Kita harus melatih kedua kaki kita supaya dapat mengumpan dengan baik.

Menurut (Skogvang, 2000) Passing adalah keterampilan ovensif yang paling umum digunakan dalam sepak bola. Tanpa kemampuan untuk bisa melakukan passing, pemain tidak bisa menggerakkan bola ke posisi saat ingin mencetak gol. Saat mempelajari teknik yang benar untuk passing, pemain akan mempelajari teknik untuk menetapkan tujuan sesuai keinginan. Dengan mempraktikkan masing-masing teknik ini, pelatih akan meningkatkan kemampuan pemain untuk menentukan jenis passing, dan untuk menentukan lokasi terbaik mana yang bisa dilewati. pemain dapat mengembangkan keterampilan dan praktik individual ini, dalam latihan Risna Delila. Pengaruh Latihan Passing Berpasangan Statis Dan Latihan Passing Bergerak Dinamis Terhadap Ketepatan Passing Pada Permainan Futsal 
kelompok, dan melalui latihan mental dimana pemain memvisualisasikan diri dalam berbagai situasi permainan. Sebuah passing dapat dilihat sebagai bentuk komunikasi antara dua pemain, orang yang mengoper dan penerima. Saat mengoper bola ke rekan satu tim, cara untuk melewatinya bisa memberi sinyal informasi. Pemain bisa melewati bola langsung pada rekan satu tim, menandakan bahwa bola harus dihentikan atau penerima bisa masuk ke kedua arah. Jika bisa melewati bola sedikit di depan rekan setimnya, menandakan bahwa pemain lain harus menerimanya dengan tenang dan terus menuju area bebas di lapangan.

Menurut (Nugraha Cipta,Andi, 2013) mengoper dan menempatkan posisi adalah salah satu kunci dari bermain olahraga futsal yang benar. Sehebat apapun permainan individu seorang pemain, jika ia tidak sedang mendapatkan atau menguasai bola maka ia tidak mungkin bisa mencetak gol. Tim yang efektif adalah tim yang sebaik-baiknya menggunakan ruang daerah dengan sebaik-baiknya dengan cara mengoper bola kepada pemain yang tidak dijaga. Pada saat yang bersamaan, pemain lawan harus dijaga dengan seketat mungkin. Dalam pertandingan futsal, kita harus mampu melihat ke arah bola agar bisa bermain dengan efektif. Penempatan diri yang baik akan menentukan bahwa kalian bisa melihat bola dengan jelas kemana arahnya. permainan dan menciptakan peluang untuk mencetak gol. Memiliki passing yang akurat dalam permainan futsal adalah harga mati bagi seorang pemain futsal (Timo Scheunemann, 2009).

Menurut (Sukamtasi, 2005) mengoper bola merupakan teknik dasar bermain sepakbola yang sangat banyak digunakan dalam permainan sepakbola. Maka teknik dasar mengoper bola merupakan dasar dalam permainan futsal. Seorang pemain futsal yang tidak menguasai teknik mengoper bola dengan sempurna, tidak mungkin menjadi pemain yang baik. Tim futsal yang baik dan tangguh adalah suatu tim yang semua pemainnya menguasai teknik dasar mengoper bola dengan baik, dengan cepat, cermat dan tepat pada sasaran, sasaran pada teman maupun sasaran dalam membuat gol ke mulut gawang lawan. Untuk dapat bermain cepat pemain harus menguasai semua gerakan-gerakan dari teknik dasar bermain futsal dan terampil memainkan bola dalam segala situasi dan posisi dalam permainan, tidak melakukan gerakan-gerakan yang tidak perlu, kecuali memperlambat gerakan juga akan membuang waktu dan tenaga. Pada waktu mendapatkan operan bola dari teman, pemain harus segera lari menjemput bola dan saat Risna Delila. Pengaruh Latihan Passing Berpasangan Statis Dan Latihan Passing Bergerak Dinamis Terhadap Ketepatan Passing Pada Permainan Futsal

Page | 33 
menerima bola segera dikontrol. Setelah satu kali sentuhan, bola harus dengan cepat segera dioperkan kepada teman atau bola segera ditembakkan ke mulut gawang, yang diteruskan dengan gerak lanjutan lari untuk mencari posisi dalam bermain.

Menurut Koger (2005:19) mengoper berarti memindahkan bola dari kaki ke kaki pemain lain dalam 1 tim, dengan cara menendangnya. Ketepatan atau akurasi tendangan sangat diperlukan agar pemain dapat mengoper bola kepada pemain lain dan melakukan tembakan yang jitu ke arah gawang tim lawan. Adapun konsep dasar yang harus dikuasai adalah: (1) anda harus mengoper atau menendng bola ke arah kaki pemain lain dalam tim anda. Jika tembakan tidak akurat, teman anda akan kesulitan menangkap bola itu, (2) tubuh anda harus mengarah ke arah bola, sementara lutut anda harus ditekuk ke arah bola, (3) dekatkan ujung kaki anda ke bola tersebut, dan telapak kaki harus menghadap ke arah sasaran bola, (4) sebelum menendang, pergelangan kaki harus kaku, lalu ayunkan kaki anda untuk menyelesaikan tendangan. Keterampilan mengoper bola memang wajib dikuasai pemain, tetapi pemain yang menerima bola harus dapat menghentikan atau mengendalikannya untuk menyelesaikan serangan. Pemain yang mengoper bola tidak akan bisa menarik bola sampai kembali ke sisi daerah penalti jika yang bersangkutan mencobanya sambil berlari dalam kecepatan tinggi. Sebelum mengoper bola, sang pemain mesti memperlambat larinya untuk mengembalikan keseimbangan tubuh sehingga dia mampu merubah arah dengan sesegera mungkin, satu hal yang perlu diperhatikan adalah sang pemain juga mesti menyadari bahwa bola yang ia bawa tersebut berada di sisi kaki bagian dalam.

Menurut (Andri Irawan, 2009) mengumpan adalah salah satu teknik dasar permainan olahraga futsal yang sangat dibutuhkan oleh setiap individu pemain, karena dengan lapangan yang rata dan ukuran lapangan yang kecil dibutuhkan passing yang keras dan akurat dikarenakan bola yang meluncur sejajar dengan tumit pemain, sebab hampir sepanjang permainan futsal melakukan passing. Keberhasilan mengumpan ditentukan oleh kualitasnya, ada 3 hal dalam kualitas mengumpan yaitu: (a) keras, (b) akurat, (c) mendatar.

Menurut (Gifford, 2003) keakuratan atau ketepatan passing adalah kunci untuk operan bola yang bagus. Bola harus meluncur ke arah yang inginkan tanpa adanya penyerobotan oleh pihak lawan. Operan memang Risna Delila. Pengaruh Latihan Passing Berpasangan Statis Dan Latihan Passing Bergerak Dinamis Terhadap Ketepatan Passing Pada Permainan Futsal 
harus mencapai sasarannya sehingga penerima mudah mudah untuk mengendalikannya, satu faktor penting adalah kecepatan atau laju bola. Mengoper bola menyatukan permainan sebuah tim, mengubah pertahanan menjadi serangan, membalik serangan, membalik arah permainan dan menciptakan peluang untuk mencetak gol.

Menurut (Rubianto Hadi, 2007) ketepatan (accuracy) adalah kemampuan seseorang untuk mengarahkan sesuatu sesuai dengan sasaran yang dikehendaki. Dari pengertian di atas dapat disimpulkan ketepatan (accuracy) yaitu kemampuan seseorang mengarahkan sesuatu ke arah sasaran yang ditentukan, dapat berupa jarak atau obyek langsung. Menendang merupakan teknik dengan bola yang paling banyak. Orang dapat menendang bola dengan keras karena disebabkan oleh gaya yang ditimbulkan oleh kontraksi otot, dimana sel-sel otot itu terdapat metabolisme perubahan kimiawi, dari zat kimia diubah menjadi energi (proses pembentukan ATP atau Adenosit Triphosphat).

Berdasarkan hasil observasi dan wawancara yang dilakukan tentang kesalahan passing pada futsal putri terjadi dalam keadaan pertandingan tegang karena kondisi skor imbang, mampu memenangkan pertandingan diakhir catatan waktu, terkejut saat pemain membawa bola didatangi oleh lawan atau tergesa-gesa ingin segera mencetak gol karena keegoisan pemain itu sendiri. Passing dalam futsal tidak hanya sekedar 12 kali sentuhan tetapi banyak variasi passing seperti short passing dan long passing. Maka dari itu kualitas passing harus diperbaiki sejak dini pada peserta ekstrakurikuler atau pada klub futsal putri mengingat dalam permainan futsal passing sangat sering dilakukan.

Tujuan dari penelitian ini adalah untuk mengetahui adanya pengaruh passing berpasangan statis dan passing dinamis pada peserta ekstrakurikuler futsal putri SMP Negeri 21 Malang. Manfaat yang diharapkan bisa dicapai Manfaat bagi guru yaitu agar mampu meningkatkan kualitas passing peserta ekstrakurikuler dan meminimalisir kesalahan peserta ekstrakurikuler futsal putri dalam melakukan passing. Manfaat bagi siswa yaitu siswa harus mampu mengukur kemampuan passingnya dan latihan tersebut dapat dijadikan acuan atau motivasi untuk meningkatkan kualitas passing yang dimilikinya. Manfaat bagi penulis yaitu sebagai motivasi jika penulis memiliki anak didik atau tim futsal putri untuk meningkatkan kualitas bermain timnya.

Risna Delila. Pengaruh Latihan Passing Berpasangan Statis Dan Latihan Passing Bergerak Dinamis Terhadap Ketepatan Passing Pada Permainan Futsal

Page | 35 


\section{METODE}

Metode penelitian yang digunakan dalam penelitian ini adalah eksperimen. Desain penelitian yang digunakan adalah Control Group pretest post-test Design, (Suharsimi Arikunto, 2013). Adapun desain penelitian dituangkan dalam bentuk gambar sebagai berikut:

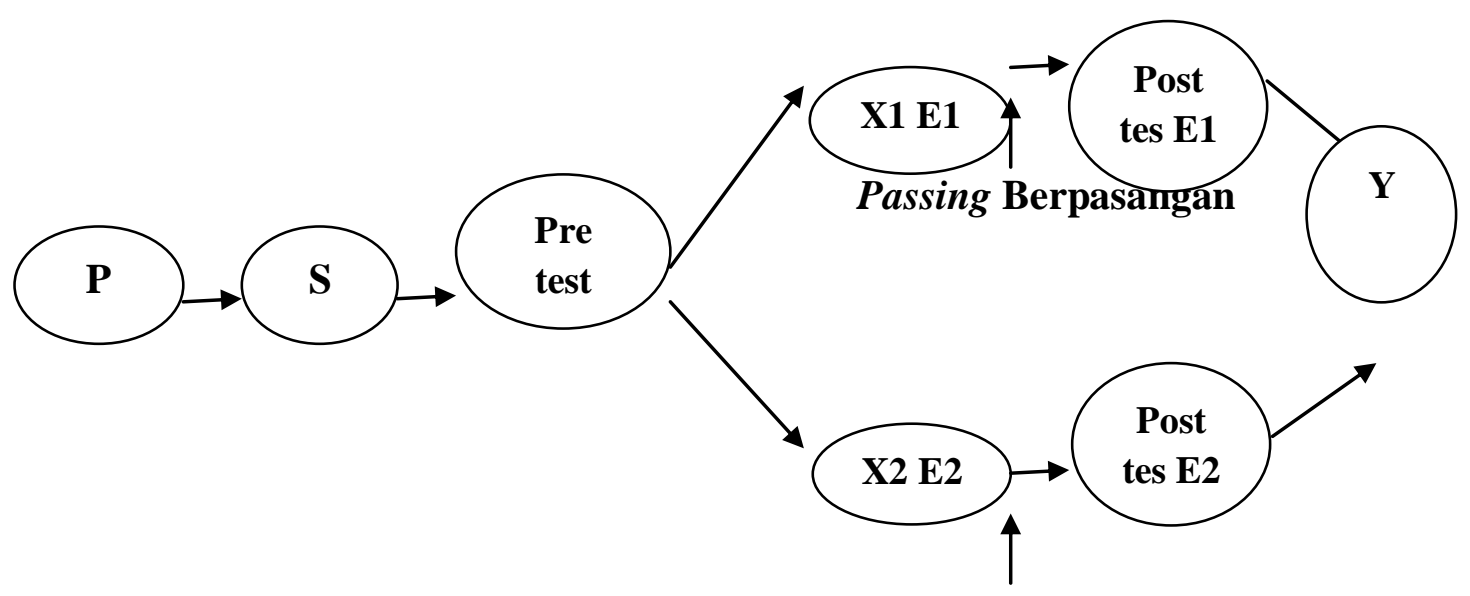

\section{Passing Bergerak}

\section{Gambar 3.1 Desain Penelitian}

( M.Zainudin, 1988 : 73 )

\section{Keterangan :}

$\mathrm{P}=$ Populasi. $\mathrm{X} 1$ = Eksperimen 1 latihan passing berpasangan.

$\mathrm{S}=$ Sampel X2 = Eksperimen 2 latihan passing bergerak.

Pretes $=$ tes awal Perlakuan $1=$ ketepatan passing bola .

Posttes $=$ tes akhir Perlakuan $2=$ ketepatan passing bola .

$\mathrm{Y}=$ tes terakhir setelah diberikan perlakuan 1 dan $2=$ ketepatan passing pada bola

Teknik pengumpulan data dalam penelitian ini menggunakan tes ketepatan passing. Data akan dikumpulkan dalam penelitian ini yaitu data pretest ketepatan passing dengan menggunakan kaki bagian dalam sebelum selesai diberikan perlakuan data postest setelah sampel diberikan perlakuan 
dengan menggunakan permainan target. Setelah itu membagi kelompok menjadi dua yaitu kelompok eksperimen 1 dan kelompok eksperimen dengan cara Ordinal Matching Pairing, masing-masing berjumlah 6 siswi dari 12 siswi.

\section{HASIL DAN PEMBAHASAN}

Data yang diambil pada saat pre-test untuk kemampuan mengumpan bola ke gawang, memiliki nilai lebih rendah dibandingkan dengan data yang diambil pada saat post-test. Hal ini berarti bahwa pada saat post-test dilaksanakan, siswi memperbaiki kemampuan mengumpan bola dengan latihan-latihan yang dilaksanakan selama masa latihan, terbukti nilai rata-rata mengumpan bola pemain pada pre-test adalah 18,5 untuk ekperimen A (passing berpasangan), 18,6 untuk eksperimen B (passing bergerak), sedangkan pada post-test adalah 27 untuk ekperimen A (passing berpasangan), 27,8 untuk eksperiment B (passing bergerak),

Setelah dilakukan pre-test pada peserta ekstrakurikuler futsal putri SMP Negeri 21 Malang, maka dapat di peroleh data bahwasanya nilai minimal untuk kemampuan mengumpan bola sebesar 14 untuk eksperimen A, 14 untuk eksperimen B, sedangkan nilai maksimal 22 untuk eksperimen A, 22 untuk nilai maksimal eksperimen B. setelah diadakan progam latihan tenyata ada peningkatan yaitu, nilai ninimal pada eksperimen A sebesar 22 m, dan nilai maksimal sebesar 29, untuk eksperimen B nilai minimal sebesar 26, untuk nilai maksimal sebesar 30 .

Tabel 1. Data Pre-Test Dan Post-Test Kemampuan Mengumpan Bola Eksperimen A Dan B

\begin{tabular}{|l|c|c|c|c|}
\hline \multirow{2}{*}{ URAIAN } & \multicolumn{2}{|c|}{ Pre-test } & \multicolumn{2}{c|}{ Post-test } \\
\cline { 2 - 5 } & Eksperimen A & Eksperimen B & Eksperimen A & Eksperimen B \\
\hline Rata-rata & 18,5 & 18,6 & 27 & 27,8 \\
Maksimal & 22 & 22 & 29 & 30 \\
Minimal & 14 & 14 & 22 & 26 \\
\hline
\end{tabular}

Setelah seluruh data didapatkan, maka tahap yang akan dikerjakan selanjutnya adalah menganalisis data. Dalam penelitian ini, analisis data dilakukan secara manual dengan menggunakan kalkulator. Hal ini dilakukan dengan alasan untuk mendapatkan tingkat penghitungan dan hasil yang lebih akurat serta mudah dipahami. 
Berdasarkan hasil penghitungan dengan menggunakan rumus uji-t, akhirnya didapatkan data hasil penghitungan uji-t untuk tes kemampuan mengumpan bola ke sasaran gawang futsal kelompok eksperimen A, memiliki nilai $t_{\text {tes }}$ sebesar 9,33, sedangkan nilai $t_{\text {tabel }}$ pada taraf signifikan 5\% dan d.b (derajat kebebasan) 12 adalah 2,782.

Tabel 2. Pre-Test Dan Post-Test Kemampuan Mengumpan Bola Eksperimen A (Latihan Passing Berpasangan)

\begin{tabular}{|c|c|c|c|c|c|}
\hline Uraian & $\begin{array}{c}\text { Rata-rata (nilai) } \\
\text { Eksperimen A }\end{array}$ & $\begin{array}{c}\mathrm{t}_{\text {tes }} \\
\text { Eksperimen A }\end{array}$ & d.b & $\mathrm{t}_{\text {tabel }}$ & $\begin{array}{c}\text { Taraf } \\
\text { Signifikan }\end{array}$ \\
\hline Pre-test & 18,5 & 9,33 & $6-1$ & 2,782 & $5 \%$ \\
Post-test & 27 & & & \\
\hline
\end{tabular}

Berdasarkan hasil tersebut, dapat disimpulkan bahwa nilai $t_{\text {tes }}$ kelompok eksperimen $A(9,33)>t_{\text {tabel }}(2,782)$, sehingga hipotesis alternatif dalam penelitian ini diterima. Hal ini berarti ada pengaruh latihan passing berpasangan terhadap ketepatan passing pada peserta ekstrakurikuler futsal putri SMP Negeri 21 Malang.

Tabel 3. Pre-Test Dan Post-Test Kemampuan Mengumpan Bola Eksperimen B (Latihan Passing Bergerak)

\begin{tabular}{|c|c|c|c|c|c|}
\hline Uraian & $\begin{array}{c}\text { Rata-rata (nilai) } \\
\text { Eksperimen B }\end{array}$ & $\begin{array}{c}\mathrm{t}_{\text {test }} \\
\text { Eksperimen B }\end{array}$ & $\mathrm{d} . \mathrm{b}$ & $\mathrm{t}_{\text {tabel }}$ & $\begin{array}{c}\text { Taraf } \\
\text { Signifikan }\end{array}$ \\
\hline Pre-test & 18,6 & 8,33 & $6-1$ & 2,782 & $5 \%$ \\
Post-test & 27,8 & & & \\
\hline
\end{tabular}

Penghitungan uji-t untuk tes ketepatan passing bola eksperimen $\mathrm{B}$, memiliki nilai $\mathrm{t}_{\text {tes }}$ sebesar 8,33, sedangkan nilai $\mathrm{t}_{\text {tabel }}$ pada taraf signifikan 5\% dan d.b (derajat kebebasan) 12 adalah 2,782. Berdasarkan hasil tersebut, dapat disimpulkan bahwa nilai $t_{\text {tes }}$ kelompok eksperimen $\mathrm{B}(8,33)>t_{\text {tabel }}$ $(2,782)$, sehingga hipotesis alternatif dalam penelitian ini diterima. Hal ini berarti ada pengaruh latihan passing bergerak terhadap ketepatan passing pada peserta ekstrakurikuler futsal putri SMP Negeri 21 Malang.

Selanjutnya, untuk mengetahui perbedaan pengaruh dari masingmasing variabel bebasnya (latihan passing berpasangan danpassing 
bergerak) terhadap variabel terikatnya (ketepatan passing), maka peneliti menggunakan analisis beda mean (Suharsimi Arikunto, 2002).

Tabel 4. Uji beda mean kedua kelompok eksperimen A dan B Hasil Analisis Beda Mean Post-Test Kedua Kelompok Eksperimen

\begin{tabular}{|c|c|c|c|c|c|c|c|}
\hline \multirow[b]{2}{*}{ Data } & \multirow{2}{*}{$\begin{array}{l}\text { Rata- } \\
\text { rata Pree } \\
\text { tes }\end{array}$} & \multirow{2}{*}{$\begin{array}{l}\text { Rata- } \\
\text { rata } \\
\text { Pos tes }\end{array}$} & \multirow[b]{2}{*}{ Hasil $t_{\text {tes }}$} & \multirow{2}{*}{$\begin{array}{c}\text { Hasil Uji Beda } \\
\text { Mean Kedua } \\
\text { Variabel }\end{array}$} & \multirow[b]{2}{*}{ d.b } & \multicolumn{2}{|c|}{$\mathrm{t}_{\text {tabel }}$} \\
\hline & & & & & & $\begin{array}{c}\text { Taraf } \\
\text { Signifikan 5\% }\end{array}$ & $\begin{array}{c}\text { Taraf } \\
\text { Signifikan } 1 \%\end{array}$ \\
\hline $\begin{array}{c}\text { Eksperimen } \mathrm{A} \\
\left(\mathrm{X}_{1}\right)\end{array}$ & 18,5 & 27 & 9,33 & & & & \\
\hline $\begin{array}{c}\text { Eksperimen B } \\
\left(\mathrm{X}_{2}\right)\end{array}$ & 18,6 & 27,8 & 8,33 & 0,226 & $12-1$ & 2,782 & 3,081 \\
\hline
\end{tabular}

Sesuai dengan tabel di atas, dapat disimpulkan bahwa ada perbedaan pengaruh antara latihan passing berpasangan dan passing bergerak terhadap ketepatan passing pada peserta ekstrakurikuler futsal putri SMP Negeri 21 Malang. Hal ini dapat dilihat berdasarkan kedua kelompok eksperimen yang setelah dihitung menggunakan rumus uji beda mean mendapatkan nilai $t_{\text {tes }}$ sebesar $0,226<\operatorname{ts}_{5 \%}(2,782)$ dan ts $_{1 \%}(3,081)$, sehingga hipotesis alternative (Ha) diterima dan hipotesis nihil (Ho) ditolak.

\section{SIMPULAN}

Berdasarkan data hasil penelitian, analisis data dan pembahasan, maka penulis dapat mengemukakan kesimpulan-kesimpulan sebagai berikut : 1) Ada pengaruh latihan passing berpasangan statis terhadap hasil ketepatan passing dalam permainan futsal, 2) Ada pengaruh latihan passing bergerak dinamis terhadap hasil ketepatan passing dalam permainan futsal, 3) Tidak ada perbedaan yang signifikan antara pengaruh latihan passing berpasangan statis dan passing bergerak dinamis terhadap ketepatan passing.

Dalam penelitian ini, peneliti juga menyimpulkan bahwa olahraga yang digunakan untuk prestasi maupun kesehatan harus berpedoman terhadap program latihan serta prinsip-prinsip latihan yang harus dipahami. Adapun program latihan yang dimaksud adalah cara seorang pelatih untuk mempersiapkan atlitnya guna menunjang latihan yang telah direncanakan atau terprogram. Misal frekuensi, intensitas, repetisi, interval, set, dan durasi merupakan susunan yang harus dipahami betul dalam menyusun program latihan.

Atas dasar penelitian ini, maka ada beberapa hal yang dapat dijadikan sebagai bahan pertimbangan sekaligus sebagai masukan bagi pengembangan 
proses penelitian pada umumnya dan pembinaan olahraga prestasi pada khususnya. Adapun hal-hal tersebut antara lain diharapkan hasil penelitian ini dapat dijadikan sebagai acuan untuk memotivasi diri guna lebih meningkatkan kemampuan dalam melakukan ketepatan passing, khususnya melalui perencanaan dan pelaksanaan program-program latihan, baik fisik maupun teknik. Salah satunya melalui pelaksanaan latihan passing berpasangan dan passing bergerak menggunakan kaki bagian dalam. Dengan demikian, diharapkan prestasi permainan olahraga futsal dapat dicapai secara maksimal melalui event pertandingan yang diikuti, hendaknya hasil penelitian ini dapat dijadikan sebagai informasi dasar mengenai keterampilan passing sehingga pembinaan olahraga prestasi dapat lebih dimaksimalkan, pada kegiatan pembinaan permainan futsal, diharapkan pelatih lebih dapat mengembangkan lagi pola-pola latihan atau pembinaan yang digunakan atau diterapkan, agar semua pemain lebih dapat menguasai teknik-teknik permainan futsal secara maksimal, hasil penelitian ini dapat dijadikan suatu referensi maupun tolok ukur guna pengembangan hasil penelitian yang lebih baik lagi, penggunaan populasi atau sampel dalam jumlah yang lebih besar dan heterogen, serta divariasikan dengan kelompok kontrol bagi peneliti yang meneliti penelitian serupa, guna pengembangan hasil penelitian yang lebih maksimal, dapat menambah khasanah pengetahuan maupun wawasan akan pentingya pendidikan jasmani dan olahraga, yaitu berkaitan dengan manfaat tubuh bugar dan sehat, serta pengembangan olahraga prestasi.

\section{DAFTAR PUSTAKA}

Arikunto, Suharsimi. 2013. Prosedur Penelitian Suatu Pendekatan Praktik. Jakarta: Rineka Cipta

Gifford, Clive. 2003. SEPAK BOLA Panduan Lengkap Untuk Permainan Yang Indah. Jakarta: Penerbit Erlangga.

Irawan, Andri. 2009. Teknik Dasar Modern Futsal. Jakarta. PENA ilmu dan amal.

Koger, Robert. 2005. Latihan Dasar Sepakbola Remaja Andal. USA: Saka Mitra Kompetensi

Murhananto. 2008. Dasar-Dasar Permainan Futsal. Jakarta: PT Kawan Pustaka.

Nugraha Cipta, Andi. 2013. Mahir Sepak Bola. Bandung: Nuansa Cendekia

Risna Delila. Pengaruh Latihan Passing Berpasangan Statis Dan Latihan Passing Bergerak Dinamis Terhadap Ketepatan Passing Pada Permainan Futsal 
Rubianto Hadi. 2007. Ilmu Kepelatihan Dasar. Semarang: Rumah Indonesia

Scheuneman, T. 2009. FUTSAL FOR WINNERS Taktik dan Variasi Latihan Futsal. Malang: Dioma

Scheuneman, T. 2012. Kurikulum dan Pedoman Dasar Sepakbola Indonesia. Jakarta: PSSI

Skogvang, Bente. 2000. Soccer Today. USA : Wadsworth Learning

Sukamtasi, Drs. 2005. Permainan Besar 1 Sepakbola. Jakarta: Universitas Terbuka 